\title{
A CONTINUOUS METHOD FOR MEASURING ACETY- LENE IN EXPIRED GAS USING GLOW DISCHARGE AND ITS APPLICATION TO ASSESSMENT OF PULMONARY BLOOD FLOW*
}

\author{
Tomiyasu Koyama and Susumu NaKaJIMA \\ Research Institute of Applied Electricity, \\ Hokkaido University, Sapporo, Japan
}

\begin{abstract}
Summary In order to measure a rapid change in pulmonary blood flow the suitability of a glow discharge gas analyser for the continuous analysis of $\mathrm{C}_{2} \mathrm{H}_{2}$ was examined. The analyser was originally designed for continuous analyses of $\mathrm{O}_{2}$ and $\mathrm{CO}_{2}$ in expired air. However, we found that it responded specifically to $\mathrm{C}_{2} \mathrm{H}_{2}$, when a gas mixture containing $5 \% \mathrm{O}_{2}, 40 \% \mathrm{CO}_{2}$ with a balance of $\mathrm{N}_{2}$ was used as a carrier gas and a negative voltage of $20 \mathrm{~V}$ was applied to the proximal collector electrode against the distal. Under these conditions the $\mathrm{C}_{2} \mathrm{H}_{2}$ current was reproducible within $0.1 \mathrm{mmHg}$, the base line drift was smaller than $1 \mathrm{mmHg} / \mathrm{hr}$ and the $90 \%$ response time was about $0.6 \mathrm{sec}$. This method was applied to analysis of $\mathrm{C}_{2} \mathrm{H}_{2}$ in expired air in combination with a constant rate expiration technique. When a $\mathrm{C}_{2} \mathrm{H}_{2}$ gas mixture was inhaled and expired at a constant rate, the observed $\mathrm{C}_{2} \mathrm{H}_{2}$ curves agreed with the theoretical ones calculated at the pulmonary blood flow rates obtained separately with the conventional breath-holding method. The decay rate of the $\mathrm{C}_{2} \mathrm{H}_{2}$ curve showed a rapid change within $1.5 \mathrm{sec}$ when exercise and a Valsalva-like maneuver were made during continuous expiration, suggesting a quick alternation in pulmonary blood flow.
\end{abstract}

During the analyses of $\mathrm{O}_{2}$ and $\mathrm{CO}_{2}$ in expired air using the glow discharge analyser elaborated by Mochizuki and co-workers (MochIZUKI and KAWAKAMI, 1965; MochizUKi and NitTA, 1967; NitTA and Mochizuki, 1969; MochizUKI et al., 1969; MochIZUKI and KAKIUCHI, 1973) we found that the analyser showed a signal current proportional to acetylene concentration in expired gas. It has often been thought that the continuous analysis of $\mathrm{C}_{2} \mathrm{H}_{2}$ would be of great value in respiratory physiology because such a technique would make possible the

Received for publication February 22, 1974

* Supported in part by a Grant No 857010 from the Ministry of Education.

小山富康, 中島 進 
instantaneous measurement of the pulmonary blood flow. Hitherto $\mathrm{C}_{2} \mathrm{H}_{2}$ has been analysed by using a Haldane gas analyser or a gas chromatograph, both of which require more than $10 \mathrm{~min}$ for one analysis. If acetylene in expired gas can be analysed rapidly, it may permit the estimation of the change of $\mathrm{C}_{2} \mathrm{H}_{2}$ concentration in the alveolar air precisely during an entire course of exhalation. Since the alveolar $\mathrm{C}_{2} \mathrm{H}_{2}$ concentration during expiration depends on both the expiration rate and its uptake rate by the pulmonary blood, the pulmonary blood flow can be estimated from the expired $\mathrm{C}_{2} \mathrm{H}_{2}$ fraction if the expiration rate is maintained constant.

In the present study the optimal conditions of the glow discharge gas analyser for a rapid and continuous analysis of $\mathrm{C}_{2} \mathrm{H}_{2}$ were first investigated. Then this method was applied to observation of the pulmonary blood flow under conditions where the expiration rate was maintained constant.

\section{METHODS}

Analysis of acetylene. The glow discharge analyser is illustrated schematically in Fig. 1. The main part of this analyser is a glow discharge tube which is connected to a vacuum pump at one end and with a thin metal tube (internal diameter of $0.3 \mathrm{~mm}$ and length of $200 \mathrm{~mm}$ ) at the other as the inlet of the carrier gas. Through this thin tube a $\mathrm{C}_{2} \mathrm{H}_{2}$ free carrier gas is sucked into the discharge tube. Since the thin tube acts as a resistance against the gas inflow, a gas pressure as low as 4 to $5 \mathrm{mmHg}$ can be maintained in the discharge tube. The discharge electrodes were located facing each other on the side wall of the tube. Between these electrodes a high frequency discharge voltage $(1 \mathrm{MHz}, 1.3 \mathrm{kV})$ is applied from an oscillator. When a glow discharge takes place inside the tube, metastable ions can be detected as a current flowing through two collector electrodes placed in the discharge tube at a part distal to the glow discharge field. The proximal collector electrode $C E 1$ is grounded through a potentiometer $P$ by which the potential difference between two collector electrodes (collector voltage) is varied. The distal collector $C E 2$, connected to ground through a resistance of 1,000 Mohms, was led directly to an IC amplifier for detecting the ionic current. Since the $\mathrm{C}_{2} \mathrm{H}_{2}$ current was much affected by the collector voltage, it was varied from 170 to $-25 \mathrm{~V}$ for finding out the optimal value. When used for measurements of expired $\mathrm{C}_{2} \mathrm{H}_{2}$ concentration $-20 \mathrm{~V}$ was usually applied to the electrode. The discharge tube is connected to another thin metal tube $M T$ (internal diameter of $0.18 \mathrm{~mm}$ and length of $200 \mathrm{~mm}$ ) through which a small amount of gas to be analysed is sampled at a constant rate $(14 \mathrm{ml} / \mathrm{min})$. The sample gas is mixed with carrier gas at a constant ratio $(14: 100)$ and then brought into the discharge field.

The ionic current is mainly affected by $\mathrm{O}_{2}$ and $\mathrm{CO}_{2}$ coexisting in the expired gas. Therefore, in order to obtain a signal current responding specifically to $\mathrm{C}_{2} \mathrm{H}_{2}$ it is necessary to suppress the $\mathrm{O}_{2}$ and $\mathrm{CO}_{2}$ effects on the ionic current. One method of achieving this is to employ gas mixtures of $\mathrm{O}_{2}$ and $\mathrm{CO}_{2}$ of various 
compositions as the carrier gas and examine the signals for $\mathrm{O}_{2}, \mathrm{CO}_{2}$ and $\mathrm{C}_{2} \mathrm{H}_{2}$ in the sample gas. Thus, the mixtures with $\mathrm{CO}_{2}$ fractions of $\mathrm{O}, 15.7,29.2$ and $48.6 \%$ were prepared for the carrier gas with the $\mathrm{O}_{2}$ fractions of 5.0 to $5.2 \%$ and $\mathrm{N}_{2}$ as a balance. The following two test gases were prepared for the sample gas: 1) $0 \% \mathrm{C}_{2} \mathrm{H}_{2}, 5.56 \% \mathrm{CO}_{2}, 15.08 \% \mathrm{O}_{2}$ and $79.36 \% \mathrm{~N}_{2}$ and 2$) 4.62 \% \mathrm{C}_{2} \mathrm{H}_{2}, 17.70 \%$ $\mathrm{O}_{2}$ and $77.68 \% \mathrm{~N}_{2}$. As a result of the measurement of this series it was found that a gas mixture containing $39.50 \% \mathrm{CO}_{2}, 6.12 \% \mathrm{O}_{2}$ and $54.38 \% \mathrm{~N}_{2}$ was used as the carrier gas in both the methodological survey and the measurement of $\mathrm{C}_{2} \mathrm{H}_{2}$ concentration in the expired gas.

Measuring procedure of the pulmonary blood flow. For the blood flow measurement the subject inhaled a gas mixture with $\mathrm{C}_{2} \mathrm{H}_{2}$ as fast as possible (in 1.3 to $2.0 \mathrm{sec}$ ) from a spirometer and then began to exhale the alveolar gas at a constant flow rate of 80 to $90 \mathrm{ml} / \mathrm{sec}$. The flow rate was controlled by a constant flow valve (OSBORN et al., 1968) placed between the mouth and a pneumotachograph. A thin polyethylene tube was inserted into the tubing connecting the constant flow valve and pneumotachograph. Through the thin polyethylene tube a small fraction of the expired gas $(3 \mathrm{ml} / \mathrm{sec})$ was drawn by the suction pump and at the joint space $J S$ a small fraction was led through the thin metal tube $M T$ into the glow discharge tube. Water vapour in the expired gas was removed by the use of a semiconductor cooling unit inserted between the constant flow valve and the glow discharge analyser. Condensed water in the cooling unit was trapped in a glass bottle attached to the cooling unit. Moreover, in order to eliminate the occasional inflow of the water drop into the joint space $S J$ and further into the glow discharge field, the joint space was made conical as shown in Fig. 1.

The measurements were made in two normal adult subjects 1) at rest in an upright position, 2) at a transition stage from rest to exercise, 3) during steady exercise and 4) when the intrathoracic pressure was abruptly increased. Exercise was performed by the subjects running on a treadmill. At stage 2) the subjects first started at a standing rest state and then began running on the treadmill, keeping their expiration at a constant rate. At the Valsalva-like manoeuver of the fourth stage the mouth pressure was measured using an electric manometer, assuming that the mouth pressure represented the intrathoracic pressure. The subjects began expiration at the mouth pressure of 4 or $5 \mathrm{mmHg}$ and in $10 \mathrm{sec}$ they made the forced exhalation, causing a large increase of the mouth pressure to $40 \mathrm{mmHg}$. The forced expiration usually lasted for $10 \mathrm{sec}$, and then, the pressure was lowered. The flow rate through the Osborn's valve was constant independently of the mouth pressure.

Calculation of the theoretical $\mathrm{C}_{2} \mathrm{H}_{2}$ curve during expiration. Since the mixed venous blood contains no $\mathrm{C}_{2} \mathrm{H}_{2}$, the uptake rate of $\mathrm{C}_{2} \mathrm{H}_{2}$ by pulmonary blood flow $\dot{Q}(\mathrm{ml} / \mathrm{sec})$ should be given by $\alpha_{b} / 760 \cdot P \cdot \dot{Q}$, where $\alpha_{b}$ is the solubility of $\mathrm{C}_{2} \mathrm{H}_{2}$ in the blood at $1 \mathrm{~atm}$ and the body temperature $\left(0.740 \mathrm{ml} \mathrm{C}_{2} \mathrm{H}_{2}\right.$ STPD/ml blood) 


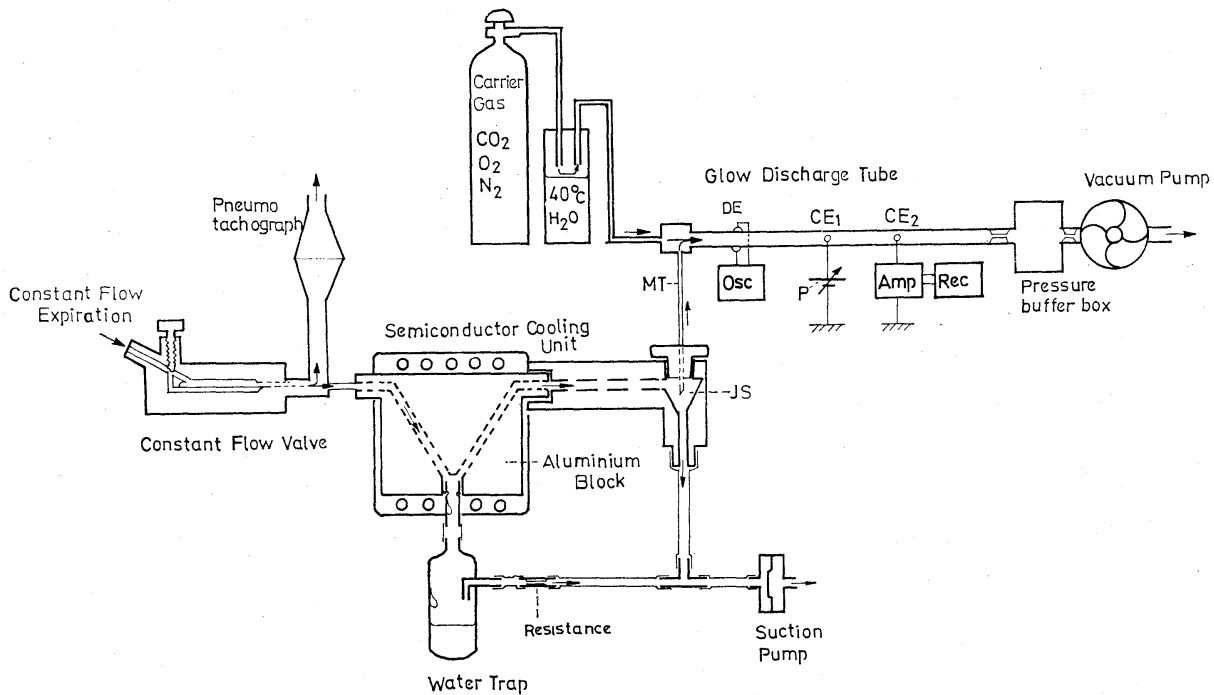

Fig. 1. Schematic illustration of the apparatus. $\mathrm{DE}$ : discharge electrodes, $\mathrm{CE}_{1}$ and $\mathrm{CE}_{2}$ : the proximal and distal collector electrodes. JS: joint space for sampling of small fraction of sample gas, MT: thin metal tube for sample inlet and P: potentiometer.

and $P(\mathrm{mmHg})$ is the partial pressure of $\mathrm{C}_{2} \mathrm{H}_{2}$ in the alveolar air. The inspired $\mathrm{C}_{2} \mathrm{H}_{2}$ is dispersed not only in the gas phase of the lung but also into the lung tissue as clarified by CANDER and Forster (1959). The quantity dissolved in the lung tissue is proportional to the alveolar $\mathrm{C}_{2} \mathrm{H}_{2}$ tension, and is given by $P \cdot \alpha_{t} / 760 \cdot V t$, where $V t$ and $\alpha_{t}$ are the tissue volume and $\mathrm{C}_{2} \mathrm{H}_{2}$ solubility $\left(0.768 \mathrm{ml} \mathrm{C}_{2} \mathrm{H}_{2}\right.$ $\mathrm{STPD} / \mathrm{ml}$ tissue) of lung tissue, respectively. On the other hand, the $\mathrm{C}_{2} \mathrm{H}_{2}$ fraction in the alveolar air $F$ is given by $F=P /(P b-47)$, thus, the total amount of $\mathrm{C}_{2} \mathrm{H}_{2}$ $\left(V_{\mathrm{C}_{2} \mathrm{H}_{2}} \mathrm{ml} \mathrm{STPD}\right)$ in the lung is given by

$$
V_{C_{2} H_{2}}=\frac{P}{P_{b}-47} \cdot V g+P \cdot \frac{\alpha_{t}}{760} \cdot V t
$$

where $V g$ is the volume of lung gas phase ( $\mathrm{ml} \mathrm{STPD).} \mathrm{Putting} \alpha_{t}^{\prime}=\alpha_{t} \cdot(P b-47) / 760$, $V_{\mathrm{C}_{2} \mathrm{H}_{2}}$ is expressed by

$$
V_{\mathrm{C}_{2} \mathrm{H}_{2}}=F \cdot\left(V g+\alpha_{t}^{\prime} \cdot V t\right)
$$

When the alveolar gas is expired at a constant rate of $\mathrm{Ce}(\mathrm{ml} / \mathrm{sec} \mathrm{STPD})$ from the initial lung gas volume $V g_{0}$ and the initial fraction $F_{0}$, the quantity of $\mathrm{C}_{2} \mathrm{H}_{2}$ remaining in the total lung at time $t$ after onset of expiration is given by

$$
V_{C_{2} H_{2}}=F \cdot\left(V g+\alpha_{t}^{\prime} \cdot V t\right)=F_{o} \cdot\left(V g_{o}+\alpha_{t}^{\prime} \cdot V t\right)-\int_{0}^{t} F \cdot \dot{Q} \cdot \alpha_{b}^{\prime} \cdot d t-\int_{0}^{t} C e \cdot F \cdot d t
$$

where $\alpha_{b}^{\prime}$ is $\alpha_{b} \cdot(P b-47) / 760$. By differentiating Eq. (3) and putting $V g=V g_{o}-$ $C e \cdot t$, the rate of the $\mathrm{C}_{2} \mathrm{H}_{2}$ fraction change in the alveolar gas is given by 


$$
d F / d t=-\alpha_{b}^{\prime} \cdot F \cdot \dot{Q} /\left(V g_{o}+\alpha_{t}^{\prime} \cdot V t-C e \cdot t\right)
$$

Since alveolar gas arrives at the glow discharge tube after flowing through the dead space of the airway, the initial alveolar $F$ is measurable in actual analyses only at a transit time $t d$ after the onset of expiration. Therefore, for the purpose of a proper comparison of the theoretical curves with the actual records, Eq. (4) must be solved with the initial condition that $F$ is $F_{o}$ at time of $t d$. If we abbreviate the volume of dead space as $V d$, the transit time $t d$ is given by $V d / C e$. Therefore, by integrating Eq. (4) from time $t d$ to $t$, the time course of $F / F_{o}$ is given by the following equation

$$
F / F_{o}=\left[\frac{V g_{o}+\alpha_{t}^{\prime} \cdot V t-C e \cdot t}{V g_{o}+\alpha_{t}^{\prime} \cdot V t-V d}\right]^{\alpha_{b}^{\prime} \cdot \dot{Q} / C e}
$$

The $F_{o}$ was calculated by exprapolating the $\mathrm{C}_{2} \mathrm{H}_{2}$ curve to time $t d$. The lung tissue volume was assumed invariably equal to $500 \mathrm{ml}$ (FUKUI and MochizUKI, 1972).

\section{RESULTS}

The relations between the fraction of $\mathrm{CO}_{2}$ in the carrier gas and both the signal currents of $\mathrm{C}_{2} \mathrm{H}_{2}$ and $\mathrm{CO}_{2}$ at a collector voltage of $0 \mathrm{~V}$ are shown in Fig. 2.

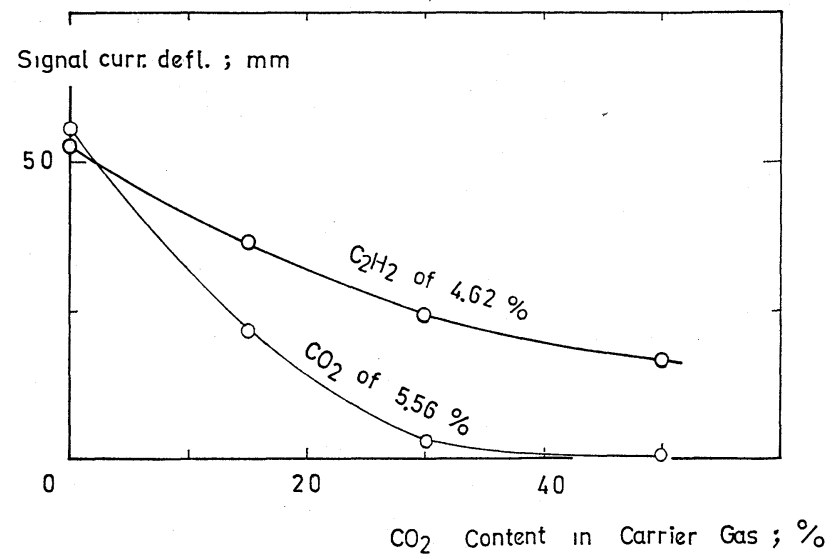

Fig. 2. Relationship between $\mathrm{CO}_{2}$ content of the carrier gas and the electric signals of the rapid gas analyser for $\mathrm{C}_{2} \mathrm{H}_{2}$ and $\mathrm{CO}_{2}$ at a collector voltage of 0 volt.

As the $\mathrm{CO}_{2}$ content of the carrier gas increased there was a reduction in both of these signal currents. The $\mathrm{CO}_{2}$ current was suppressed more than the $\mathrm{C}_{2} \mathrm{H}_{2}$ current. At a $40 \% \mathrm{CO}_{2}$ fraction of the carrier the $\mathrm{C}_{2} \mathrm{H}_{2}$ current corresponding to $4.62 \%$ $\mathrm{C}_{2} \mathrm{H}_{2}$ in the sample gas was 50 times greater than that due to $5.56 \%$ of $\mathrm{CO}_{2}$ in the sample gas. 
The effects of the collector voltage on the signal currents of $\mathrm{CO}_{2}$ and $\mathrm{C}_{2} \mathrm{H}_{2}$ were examined when $\mathrm{CO}_{2}$ fraction in the carrier gas was $40 \%$. As shown in Fig. 3, the signal currents for both the gases became small in a negative voltage range,

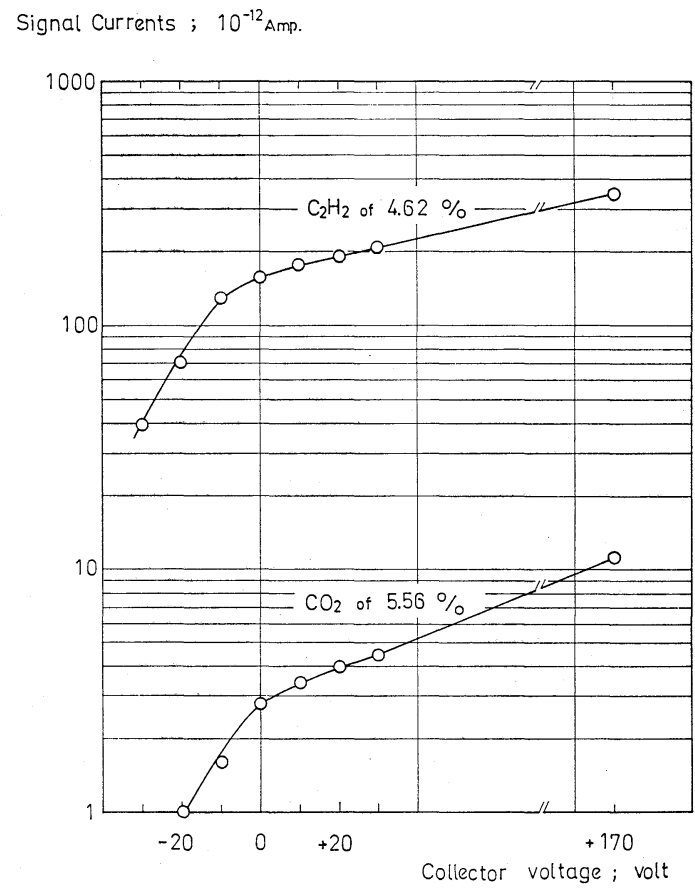

Fig. 3. Effects of collector voltage on signal currents of $\mathrm{C}_{2} \mathrm{H}_{2}$ and $\mathrm{CO}_{2}$ with a carrier gas consisting of $6.12 \% \mathrm{O}_{2}, 39.50 \% \mathrm{CO}_{2}$ and $54.38 \% \mathrm{~N}_{2}$.

but the $\mathrm{CO}_{2}$ signal current became much smaller than that for $\mathrm{C}_{2} \mathrm{H}_{2}$. At $-20 \mathrm{~V}$ the $\mathrm{CO}_{2}$ signal current was so small to be negligible in relation to that for $\mathrm{C}_{2} \mathrm{H}_{2}$. The response time of the $\mathrm{C}_{2} \mathrm{H}_{2}$ current also depended on the collector voltage. The time required for $90 \%$ response is plotted against collector voltage in Fig. 4. In a negative voltage range the response time became shorter than in a positive and it was $0.6 \mathrm{sec}$ at $-20 \mathrm{~V}$. For testing stability and reproducibility of the signal current the analyser was left in operation for more than 3 hours, and sample gases with 4 different $\mathrm{C}_{2} \mathrm{H}_{2}$ concentrations of $0.52,1.37,2.44$, and $3.19 \%$ were given intermittently and repeatedly. A section from a long-term recording is shown in Fig. 5. It was concluded that the base and signal currents were fairly stable and reproducible when the collector voltage was $-20 \mathrm{~V}$ and the $\mathrm{CO}_{2}$ fraction in the carrier gas was $40 \%$. The $\mathrm{C}_{2} \mathrm{H}_{2}$ signal current was reproducible with an error of $0.1 \mathrm{mmHg}$ and the base line drift was less than $1 \mathrm{mmHg} / \mathrm{hr}$. The calibration curve was not linear at concentrations close to $0 \%$, while it was fairly linear above $1 \%$. 


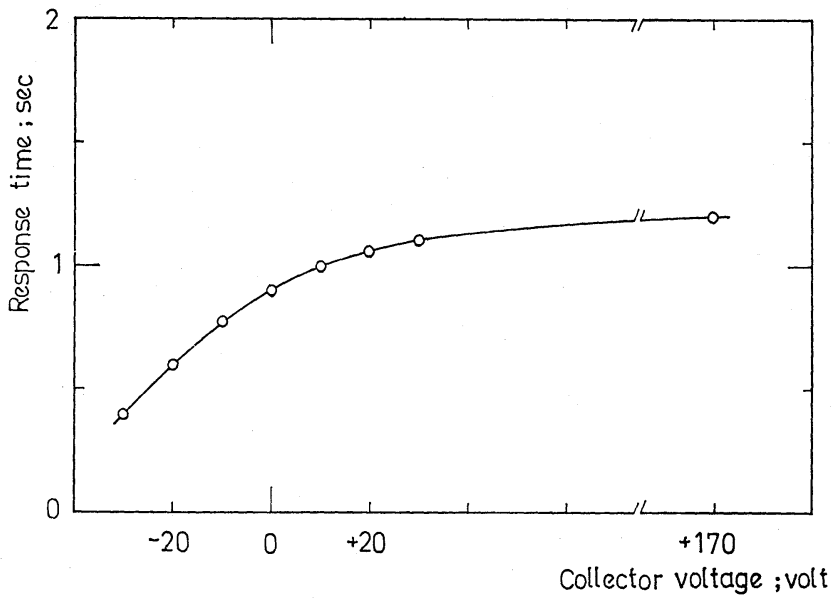

Fig. 4. Effects of collector voltage on the response time of $\mathrm{C}_{2} \mathrm{H}_{2}$ signal current at a hypercapnic carrier gas containing $39.50 \% \mathrm{CO}_{2}$.

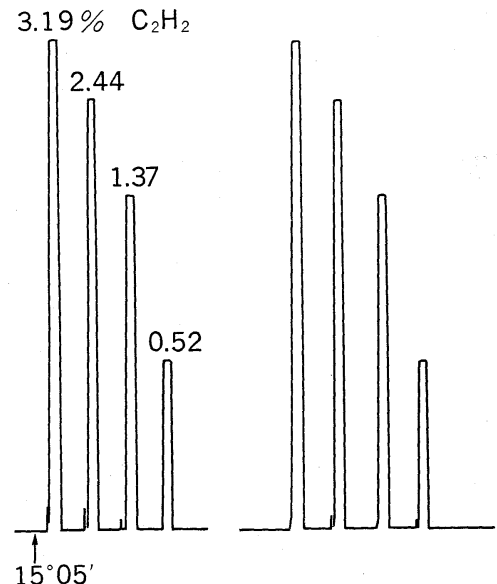

$15^{\circ} 05^{\prime}$

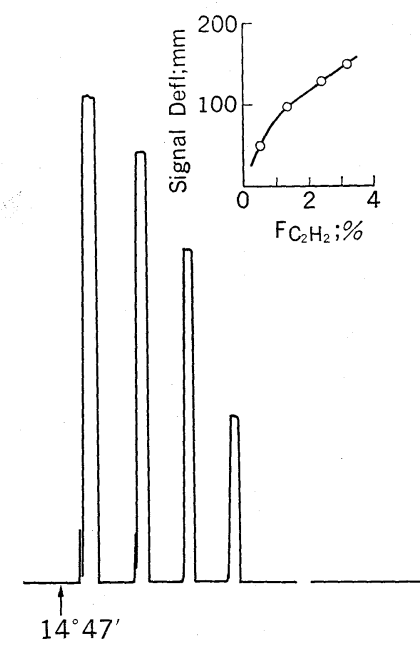

23.8.1972

Gas mixt. kept

in vinyl bag

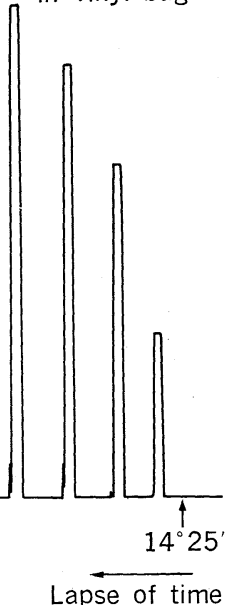

Fig. 5. A section from a long term recording and the reproducibility of $\mathrm{C}_{2} \mathrm{H}_{2}$ signal. $\mathrm{C}_{2} \mathrm{H}_{2}$ gas mixtures were analysed repeatedly at the noted clock time.

Examples of continuous analysis of the expired gas are shown in Figs. 6, 8, and 9. The curves in Fig. 6A and $\mathrm{B}$ were obtained at rest and during a steady exercise of $5 \mathrm{~km} / \mathrm{hr}$ respectively, while the expiration was maintained at a rate of $90 \mathrm{ml} /$ sec. The upper and lower curves show the flow rate and $\mathrm{C}_{2} \mathrm{H}_{2}$ fraction respectively. The decrease of $\mathrm{C}_{2} \mathrm{H}_{2}$ became steeper during exercise than at rest. The ratio of instantaneous $\mathrm{C}_{2} \mathrm{H}_{2}$ value to the initial, $F / F_{o}$, is plotted against the expiration time 


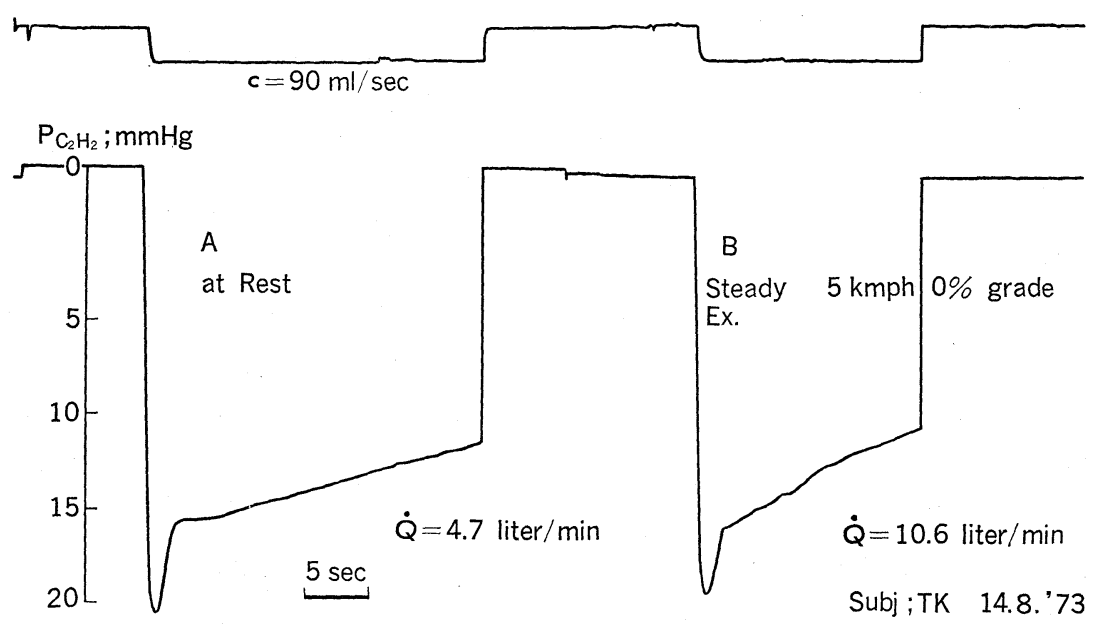

Fig. 6. Examples of actual recordings. A; at rest and B; at mild exercise of treadmill running at $5 \mathrm{~km} / \mathrm{hr}$ and $0 \%$ grade. The curves above and below show the airflow of prolonged expiration and $\mathrm{C}_{2} \mathrm{H}_{2}$ in the expired gas, respectively.

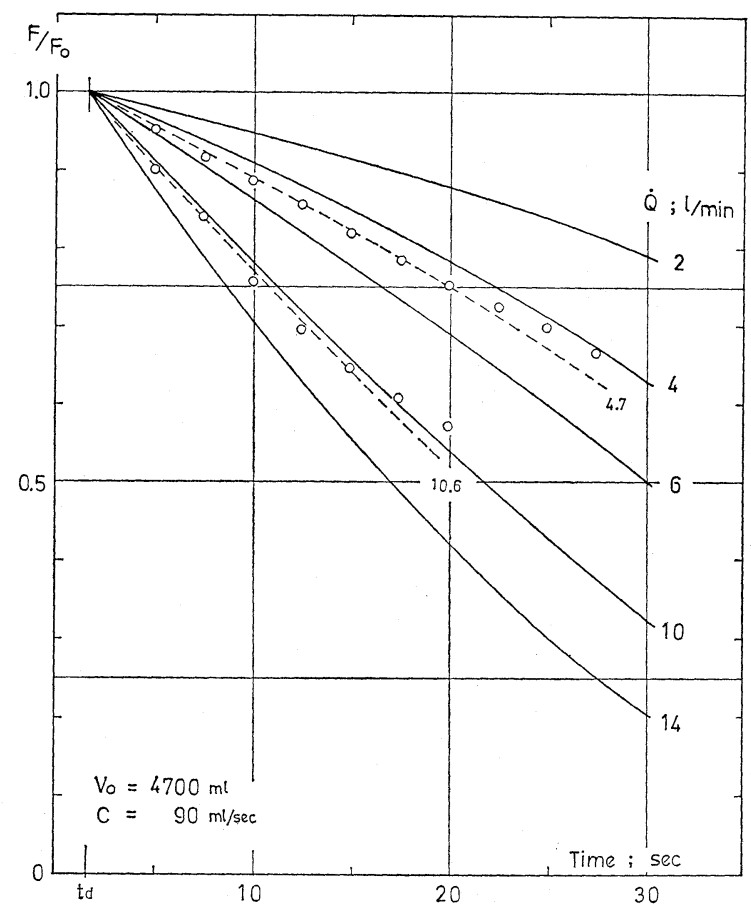

Fig. 7. Time course of $F / F_{0}$. Circles show the actually observed values and the lines were calculated from Eq. (5) for various $\dot{Q}$ 's. 
with circles in Fig. 7. The thick lines depicted in the same figure show the theoretical curves calculated from Eq. (5) at 5 different $\dot{Q}$ values by putting $V_{o}=4,700 \mathrm{ml}$ according to the actual value measured by He analysis. The measured $F / F_{o}$ values both at rest and exercise agreed well with the theoretical curves calculated at $\dot{Q}$ of 4.7 and $10.6 \mathrm{liter} / \mathrm{min}$ within time range of 0 to $20 \mathrm{sec}$ and 0 to $15 \mathrm{sec}$ respectively. The $\dot{Q}$ values measured subsequently in the same subject by the conventional $\mathrm{C}_{2} \mathrm{H}_{2}$ breath-holding method (CANDER and FORSTER, 1959) were 4.8 and 11.4 liter/min at rest and during exercise, respectively, showing agreement with the $\dot{Q}$ values estimated by the present $\mathrm{C}_{2} \mathrm{H}_{2}$ gradient method.

The $\mathrm{C}_{2} \mathrm{H}_{2}$ curves obtained at the transition stage from rest to exercise are shown in Fig. 8. At the onset of exercise the gradient of the $\mathrm{C}_{2} \mathrm{H}_{2}$ curve became clearly steep as seen in Fig. $8 \mathrm{~B}$ and $\mathrm{C}$. In addition, the $\mathrm{C}_{2} \mathrm{H}_{2}$ uptake rate during

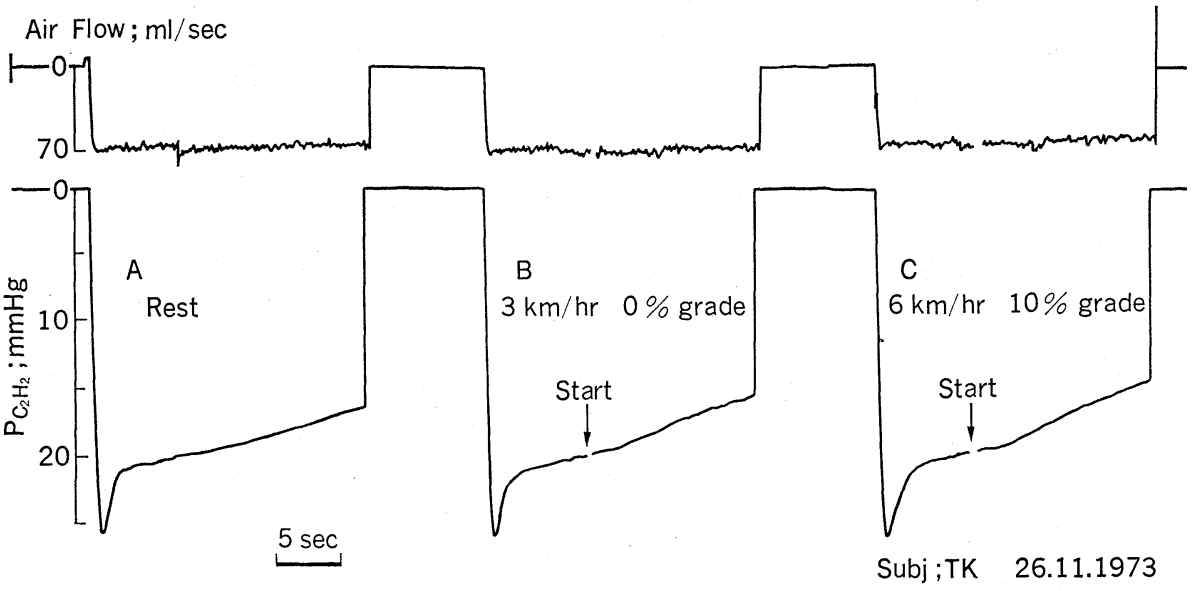

Fig. 8. Examples of actual recording of $\mathrm{C}_{2} \mathrm{H}_{2}$ decrease at transition from rest to exercise. A; at rest, $B$ and C; treadmill walking at $3 \mathrm{~km} / \mathrm{hr}$ with $0 \%$ grade and running at $6 \mathrm{~km} / \mathrm{hr}$ with $10 \%$ grade were started at the arrow, respectively.

running at a speed of $6 \mathrm{~km} / \mathrm{hr}$ and a grade of $10 \%$ shown in Fig. $8 \mathrm{C}$ was apparently larger than that obtained in the case of $8 \mathrm{~B}$ when walking at a speed of $3 \mathrm{~km} / \mathrm{hr}$. As shown in those curves the increase of the $\mathrm{C}_{2} \mathrm{H}_{2}$ uptake occurred within $2.5 \mathrm{sec}$ after the start of exercise. Since the transit time of the alveolar air through the dead space was estimated to be longer than $1 \mathrm{sec}$, the delay of appearance time of the current change from that of the alveolar $\mathrm{C}_{2} \mathrm{H}_{2}$ change would also be at least $1 \mathrm{sec}$. Thus, the increase in $\mathrm{C}_{2} \mathrm{H}_{2}$ uptake is estimated to have occurred within $1.5 \mathrm{sec}$ following onset of exercise.

An example of the $\mathrm{C}_{2} \mathrm{H}_{2}$ curves obtained in the state No. 4 where the intrathoracic pressure was abruptly increased is shown in Fig. 9. The curves show from top to bottom the a) flow rate during expiration, b) $\mathrm{C}_{2} \mathrm{H}_{2}$ concent- 


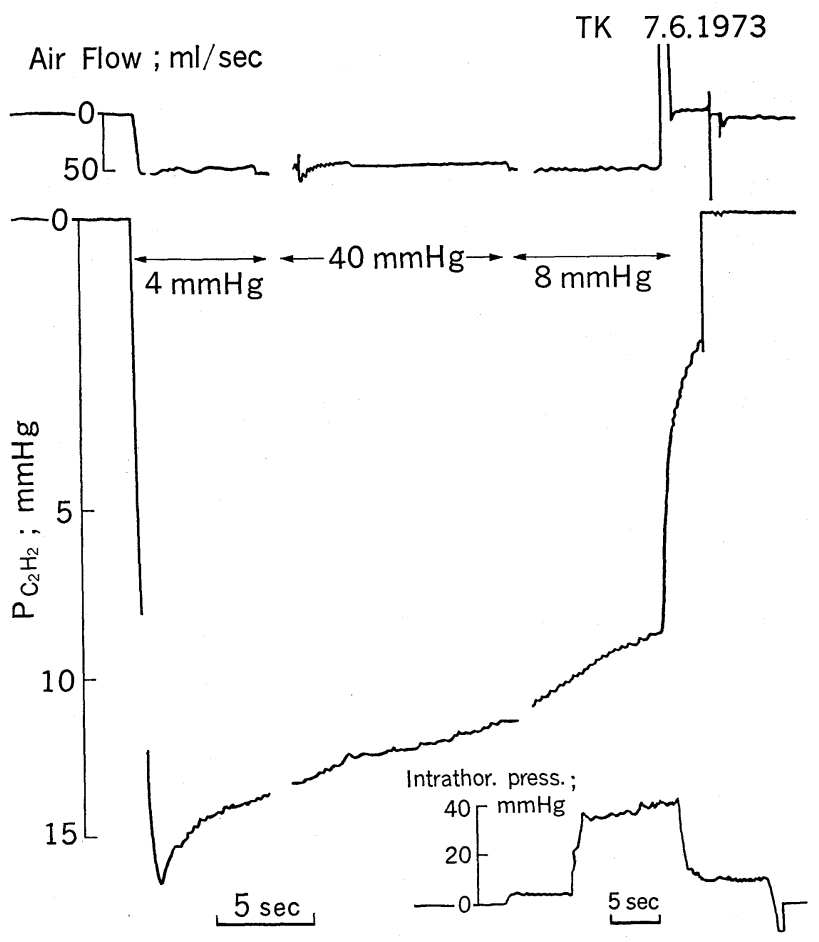

Fig. 9. Effects of intrathoracic pressure on the decay rate of $\mathrm{C}_{2} \mathrm{H}_{2}$ in the expired gas during a Valsalva-like manoeuver. The mouth pressure was first $4 \mathrm{mmHg}$ and then increased to $40 \mathrm{mmHg}$. $10 \mathrm{sec}$ thereafter the pressure was lowered to $8 \mathrm{mmHg}$. The curves from top to bottom show the flow rate of expiration, $P_{\mathrm{C}_{2} \mathrm{H}_{2}}$ and the mouth pressure. The pressure curve was displayed on another recorder at a chart speed half of the other curves and was subsequently attached to this figure.

ration both recorded at a chart speed of $240 \mathrm{~mm} / \mathrm{min}$ and c) the mouth pressure recorded on another recorder at a speed of $120 \mathrm{~mm} / \mathrm{min}$. The flow rate was kept constant by the Osborn's valve regardless of the change in the expiration effort. The $\mathrm{C}_{2} \mathrm{H}_{2}$ decrease was apparently slowed down by the elevation of the alveolar pressure and again accelerated by the reduction of the pressure.

\section{DISCUSSION}

The ionic current following glow discharge is affected by the gas species introduced into the discharge field by 1) the amount of ions produced from the introduced gas itself and 2) the recombination rate of the ionized gas molecules. In the present study $\mathrm{C}_{2} \mathrm{H}_{2}$ caused an increase of the ionic current, suggesting that $\mathrm{C}_{2} \mathrm{H}_{2}$ molecules are ionized by the glow discharge much more easily than the gas mixtures of $\mathrm{N}_{2}, \mathrm{O}_{2}$ and $\mathrm{CO}_{2}$. However, between the signal currents of $\mathrm{C}_{2} \mathrm{H}_{2}$ and 
the discharge field intensity no specific correlation was observed. Therefore, it was necessary to suppress the unwanted signals of other gas species than $\mathrm{C}_{2} \mathrm{H}_{2}$. According to MochIZUKI and NiTTA (1967), when a gas mixture consisting of $\mathrm{CO}_{2}$ and $\mathrm{N}_{2}$ was used as the carrier gas, the signal responding to $\mathrm{O}_{2}$ became observable, and in a similar manner the signal current for $\mathrm{CO}_{2}$ appeared when the carrier gas contained $\mathrm{O}_{2}$ and $\mathrm{N}_{2}$. Following their finding, in our effort to find out the optimal conditions for continuous $\mathrm{C}_{2} \mathrm{H}_{2}$ analysis, we examined the effects of carrier gases containing both $\mathrm{O}_{2}$ and $\mathrm{CO}_{2}$ on the signal current for $\mathrm{C}_{2} \mathrm{H}_{2}$. As a result it was found that the current specifically responded when a gas mixture consisting of $5 \%$ $\mathrm{O}_{2}, 40 \% \mathrm{CO}_{2}$ and a balance of $\mathrm{N}_{2}$ was used as the carrier gas. Moreover, the collector voltage showed a remarkable effect on both the $\mathrm{C}_{2} \mathrm{H}_{2}$ and $\mathrm{CO}_{2}$ currents, and the latter current was almost eliminated, when $-20 \mathrm{~V}$ was applied to the proximal collector electrode against the distal. In detail, however, the $\mathrm{CO}_{2}$ signal current responding to $5.56 \% \mathrm{CO}_{2}$ in the sample gas caused a $1.2 \%$ relative error to the signal current responding to $4.62 \% \mathrm{C}_{2} \mathrm{H}_{2}$. In order to minimize the above error, gas mixtures with 4 to $5 \% \mathrm{CO}_{2}$ which corresponded to the $\mathrm{CO}_{2}$ content in the expired gas were used for calibration of the $\mathrm{C}_{2} \mathrm{H}_{2}$ concentration of expired gas. Since water vapour also affected the ionic currents, a simple water elimination unit was designed and attached to the analyser as shown schematically in Fig. 1. Thus, the sample gas flows through a V-shaped passage bored in the aluminium block which was cooled at $0.5^{\circ} \mathrm{C}$ by the use of a semiconductor cooling unit. A part of the sample gas was sucked out from the opening at the bottom of the passage and brought the condensed water into the trap bottle. Thus, the water content of the sample gas was kept sufficiently low for practical usage.

The present method is suited especially to the continuous analysis of $\mathrm{C}_{2} \mathrm{H}_{2}$ in the expired gas. To demonstrate this merit, it was used for observations on the expired $\mathrm{C}_{2} \mathrm{H}_{2}$ concentration during a constant rate expiration. For examining the validity of this method the change in $\mathrm{C}_{2} \mathrm{H}_{2}$ fraction in expired gas, $F / F_{0}$, was compared with the theoretically calculated curves. As shown in Fig. 7 the $F / F_{o}$ values at rest and during exercise fell on the theoretical curves calculated from Eq. (5) by putting $\dot{Q}=4.7$ and $10.6 \mathrm{liter} / \mathrm{min}$, which agreed closely with the $\dot{Q}$ values obtained subsequently in the same conditions by the breath-holding method. In 15 to $20 \mathrm{sec}$ after the onset of expiration the observed points began to deviate from the theoretical curves probably because of recirculation of the pulmonary blood. The above agreement suggests that with this method it is possible to measure the pulmonary blood flow instantaneously from the $\mathrm{C}_{2} \mathrm{H}_{2}$ curves. Furthermore, the rapid changes appearing at the transition from rest to exercise or by the Valsalva-like manoeuver clearly support the fidelity of the flow measurement. At the onset of exercise the increase of $\mathrm{C}_{2} \mathrm{H}_{2}$ uptake occurred within $1.5 \mathrm{sec}$, indicating a rapid reaction of the pulmonary blood flow to the exercise.

NinOMIYA and WiLSON (1966) made a similar observation in dogs by the use of an implanted magnetic flow meter that heart rate was promptly increased at 
the onset of exercise. The interval between the first and second heart beats immediately after the onset of exercise was markedly reduced. In 7 to 10 secs the cardiac output reached a level of $63.2 \%$ of the maximum value observed at the given work load. The present findings suggest that such a rapid reaction also occurs in human subjects.

The rapid decrease in $\dot{Q}$ caused by an elevation of intrathoracic pressure was observed by Fox et al. (1966) using a dye-dilution method. The results shown in Fig. 9 are in agreement with their findings. Above all it seems certain that the present continuous method, when combined with a constant flow expiration technique, offers a new possibility for making measurements of changes in pulmonary blood flow in man.

The authors wish to express their thanks to Prof. Masaji Mochizuki for his valuable advice and encouragement. They are much indebted also to JSPS invited Prof. G. M. Hughes, Division of Comparative Animal Respiration Physiology, University of Bristol, for his kind reading and correcting of the manuscript. They thank also Mr. Takashi Arai for his skillful aid in the construction of the apparatus.

\section{REFERENCES}

CANDER, L. and Forster, R. E. (1959) Determination of pulmonary parenchymal tissue volume and pulmonary capillary blood flow in man. J. Appl. Physiol., 14: 541-551.

Fox, I. J., Crowley, W. P., Jr., Grace, J. B., and Wood, E. H. (1966) Effects of the Valsalva maneuver on blood flow in the thoracic aorta in man. J. Appl. Physiol., 21: 1553-1560.

FukUI, K. and Mochizuki, M. (1972) Influences of ventilatory and circulatory uneveness in the lung on cardiac output values measured by a single breath method and a normal range of contact time. In Advances in Respiratory Physiology and Controls. Monogr. Ser. Res. Inst. Appl. Electr., 20: 90-100.

MochIZUKI, M. and KAWAKAMI, Y. (1965) A new detector for a gas chromatograph using electron current following glow discharge. Jap. J. Physiol., 15: 553-559.

MochizUKI, M. and NitTA, K. (1967) A continuous method for measuring $\mathrm{O}_{2}$ and $\mathrm{CO}_{2}$ in expired gas. Digest of the 7th Intern. Conf. on ME and BE. Stockholm, p. 439.

Mochizuki, M., KakiUchi, Y., NAKABaYashi, T., and Arai, T. (1969) A new method for measuring $\mathrm{O}_{2}$ and $\mathrm{CO}_{2}$ in gas by using a glow discharge. Monogr. Ser. Res. Inst. Appl. Electr., 17: $1-65$.

MochizuKi, M. and KaKiuchi, Y. (1973) A continuous method for measuring $\mathrm{O}_{2}$ and $\mathrm{CO}_{2}$ in expired and alveolar gases. In Oxygen Supply. Urban \& Schwarzenberg, München-BerlinWien, pp.92-95.

Ninomiya, I. and WiLson, M. F. (1966) Cardiac adaptation at the transition phases of exercise in unanesthetized dogs. J. Appl. Physiol., 21: 953-958.

NitTA, K. and Mochizuki, M. (1969) A continuous method for measuring $\mathrm{O}_{2}$ and $\mathrm{CO}_{2}$ in expired gas. Jap. J. Physiol., 19: 41-45.

Osborn, J. J., Shore, J. H., and ElLIot, S. E. (1968) A constant flow valve for respiratory gas sampling. J. Appl. Physiol., 24: 113-115. 